\title{
MATERIAL DIDÁTICO DO PROGRAMA NEJA - TENSÕES ENTRE POSSIBILIDADES EMANCIPATÓRIAS E CURRÍCULO PRESCRITIVO NO TRABALHO DOCENTE EM HISTÓRIA
}

\author{
EDUCATIONAL MATERIAL ON NEJA PROGRAM - ISSUES FACING \\ EMANCIPATING POSSIBILITIES AND PRESCRIPTIVE SCHOOL CURRICULUM \\ IN HISTORY EDUCATION
}

Alessandra Nicodemos ${ }^{1}$

Débora Petrillo Grasso Flor ${ }^{2}$

\begin{abstract}
RESUMO: Esse artigo problematiza elementos curriculares da política pública para a Educação de Jovens e Adultos (EJA) ofertada pela Secretaria de Estado de Educação do Rio de Janeiro, intitulada NEJA. Como elemento central de análise contrapõe o controle burocrático e pedagógico sobre o trabalho docente e as possibilidades mais autônomas e emancipatórias de uso do material didático de História, por docentes e discentes, em processos de escolarização de jovens e adultos trabalhadores. Mobilizando autores do campo educacional crítico (Saviani; Manacorda; Neves; Rummert, Algebaile e Ventura), procura através da apresentação da função social da escolarização no contexto da sociedade capitalista inferir os impactos de uma formação escolar, que na materialidade de uma dualidade educacional de novo tipo limita as possibilidades de uma formação escolar emancipatória; considerando dessa forma, o material didático do programa NEJA como a materialidade desse modelo atual de oferta para a EJA no Estado do Rio de Janeiro. Em contraponto a essa tendência, busca-se ainda, numa análise mais pormenorizada da categoria trabalho, no material didático de História, as brechas indutoras, por onde professores e educandos possam construir experiências escolares e curriculares mais emancipatórias no contexto escolar do Programa e no uso didático do referido material. Indicando, dessa forma, que currículo prescritivo e possibilidades emancipatórias podem se conjugar na escola de jovens e adultos trabalhadores, principalmente como expressão de determinadas opções didático-políticas assumida e desenvolvida por professores de História.
\end{abstract}

Palavras-Chave: Ensino de História. Educação de Jovens e Adultos. Material Didático.

ABSTRACT: This article discusses curricular elements of the public policy for Youth and Adult Education (EJA) offered by the Rio de Janeiro State Department of Education, entitled NEJA. As central element of analysis, it contrasts bureaucratic and pedagogical control over teaching work and the more autonomous and

\footnotetext{
${ }^{1}$ Doutora em Educação pela Universidade Federal Fluminense e Professora Adjunta da Universidade Federal do Rio de Janeiro.

${ }^{2}$ Especialista em Educação de Jovens e Adultos pela Universidade Federal do Rio de Janeiro e Professora da Educação Básica.
} 
emancipatory possibilities of using didactic material in History, by teachers and students, in schooling processes for young and adult workers. Mobilizing authors of the Critical educational field (Saviani; Manacorda; Neves; Rummert, Algebaile and Ventura), seeks through the presentation of the social function of schooling in the context of capitalist society infer the impacts of a school education, that in the materiality of an educational duality of new type limits the possibilities of an emancipatory school education; Considering this way, the didactic material of the NEJA program as the materiality of this current model of supply for EJA in the state of Rio de Janeiro. In contrast to this tendency, we also seek, in a more detailed analysis of the category work, in the didactic material of history, the inducing loopholes, by which teachers and students, can build school and curricular experiences more in the school context of the program and in the didactic use of the said material. Indicating, therefore, that prescriptive curriculum and emancipatory possibilities can be conjugate in the school of young and adult workers, mainly as an expression of certain didactic-political options assumed and developed by History teachers.

Keywords: Teaching History. Youth and Adult Education. Courseware.

\section{Introdução}

Esse artigo problematiza elementos curriculares da política pública para a Educação de Jovens e Adultos (EJA) ofertada pela Secretaria de Estado de Educação do Rio de Janeiro (SEEDUC/RJ), intitulada Nova Política de Educação de Jovens e Adultos (NEJA), no período de 2013 até $2016^{3}$. Procura, como elemento central de análise no artigo, tensionar o controle burocrático e pedagógico sobre o trabalho do professor - fortemente presente na estrutura política-curricular da NEJA - e as possibilidades mais autônomas e emancipatórias de uso do material didático na disciplina de História.

Dessa forma, podemos identificar que, mesmo em contextos curriculares mais prescritivos - como o modelo de política pública em tela o material didático de História da NEJA, apresenta possibilidades de uso que conseguem dialogar, em certa medida, com questões que o campo da EJA indica como fundamentais para o processo de escolarização de alunos jovens e adultos trabalhadores numa perspectiva crítica e emancipatória.

\footnotetext{
${ }^{3}$ A partir de 2016, o programa foi alterado em seu formato de oferta, passando da nomenclatura de NEJA para EJA. Essa alteração não implicou em mudanças significativas na estrutura/concepção na oferta pela SEEDUC/RJ até os dias atuais e nem no Material Didático, concebido e distribuído pela Secretaria de Educação a docentes e discentes.
}

História \& Ensino, Londrina, v. 25, n. 1, p. 139-157, jan./jun. 2019 
Como premissa inicial, nos cabe indagar: como se estabelece nos marcos de elaboração do material didático essa contradição?

A resposta a essa questão se dá, em nosso ponto de vista, no entendimento do Estado como a condensação de uma relação de forças (POULANTZAS, 1975) e não como uma estrutura monolítica de determinada força dominante socialmente. O autor marxista Nicos Poulantzas (1975), em seu texto As lutas políticas: Estado condensação de uma relação de forças, dimensiona um caráter do Estado que se afasta da tendência de identificar a dominação e controle político do Estado numa perspectiva essencialmente monolítica de interesses e de disputas. Consideramos, assim, que essa dinâmica pode ser reconhecida quando analisamos as contradições presentes na elaboração, implementação e distribuição de políticas públicas e curriculares em educação no tempo presente.

Essa perspectiva analítica considera que nos marcos da sociedade capitalista, o Estado, enquanto bloco no poder - historicamente definido nas diferentes conjunturas -, representa invariavelmente 0 projeto e os interesses do capital, e nos dias atuais do capital financeiro monopolista. Porém, dentro de sua estrutura, coexistem interesses interclasses e de suas frações em disputa. Escreve Poulantzas (1975, p. 162): "o Estado concentra não apenas a relação de forças entre frações do bloco no poder, mas também a relação de forças entre estas e as classes dominadas". Dessa forma, podemos considerar que a luta de classe constitui a estrutura do Estado e ao mesmo tempo o atravessa. Tais contradições se materializam na disputa entre as divisões internas no pessoal do Estado, que em última instância, são os responsáveis pela concepção e elaboração do material de História da NEJA. Essa aposta analítica contribui para o entendimento das contradições presentes na elaboração do material didático, que ao apresentar possibilidades emancipatórias de ensino e aprendizagem materializa uma fissura com a perspectiva prescritiva e de forte controle do programa. 


\section{NEJA: uma dualidade educacional de novo tipo}

De acordo com Saviani (2007) a relação entre educação e trabalho não pode ser vista separadamente uma da outra. Os cenários - social, político e econômico - ao longo da história vêm apresentando a ruptura dessa relação, porém que caminham juntas dentro do ponto de vista que considera que a educação é o

(...) processo que nos permite tomar consciência de nós mesmos, de nossa trajetória histórica enquanto indivíduos, nação ou mundo; das contradições e desigualdades presentes na sociedade em que vivemos; de nossas especificidades culturais (sobretudo através do conhecimento do outro) e das profundas desigualdades sociais existentes(...) (SEGNINI, p.72, 2000).

Porém, a organização societária em classes sociais e a realidade de extrema desigualdade social em sociedades periféricas como a nossa, impacta negativamente as possibilidades mais emancipatórias de educação, como indica Saviani (2007):

(...) nas sociedades primitivas, caracterizadas pelo modo coletivo de produção da existência humana, a educação consistia numa ação espontânea, não diferenciada das outras formas de ação desenvolvidas pelo homem, coincidindo inteiramente com o processo de trabalho que era comum a todos os membros da comunidade, com a divisão dos homens em classes a educação também resulta dividida; diferencia-se, em consequência, a educação destinada à classe dominante daquela a que tem acesso a classe dominada (p. 155 e 156).

Nesse debate, ainda, em uma perspectiva crítica, o trabalho pode ser concebido em outra lógica, reconhecido como princípio educativo, porém, a classe dominante conduziu a educação formal e obrigatória para uma formação que produz a unilateralidade dos sujeitos, como atesta Manacorda (1991): 
(...) todo homem, subsumido pela divisão do trabalho aparece unilateral e incompleto. Essa divisão se torna real quando se apresenta como divisão entre o trabalho manual e o trabalho mental, porque aí 'se dá a possibilidade, ou melhor, a realidade de que a atividade espiritual e a atividade material, o prazer e o trabalho, a produção e 0 consumo se apliquem a indivíduos distintos (p. 46).

Assim, o processo de escolarização que apresenta em seus princípios a formação do homem unilateral pretende à preparação para o trabalho alienado, ou seja, a formação que prepara para o mercado de trabalho na qual o homem vende a sua mão de obra e aceita a sua realidade. Em possibilidade oposta temos a formação omnilateral que é "(...) a chegada histórica do homem a uma totalidade de capacidades produtivas e, ao mesmo tempo, a uma totalidade de capacidades de consumo e prazeres, em que se deve considerar, sobretudo o gozo daqueles bens espirituais, além dos materiais, e dos quais o trabalhador tem estado excluído em consequência da divisão do trabalho" (MANACORDA, 1991, p. 89).

A formação omnilateral está voltada para constituir o homem consciente dos problemas do seu tempo, do seu mundo, tornando-o capaz de realizar críticas a sua realidade social e na qual possa compreender e intervir, além de tomar decisões que visem à humanização e a emancipação social:

(...) formar hoje para uma perspectiva omnilateral, e dentro de uma concepção de que as pessoas vêm em primeiro lugar, pressupõe tornar-se senso comum de que as relações capitalistas são incapazes, por natureza intrínseca, de prover minimamente o conjunto de direitos fundamentais a todos os seres humanos, a começar pelo direito à vida digna, à saúde, à educação, habitação, emprego ou salário desemprego, lazer, etc., sem o que o humano se atrofia (FRIGOTTO,1996, p. 157).

É valido pensar em uma escola de jovens e adultos, que não abra mão de ser uma instituição mantedora do conhecimento científico, mas que reconheça e valorize os saberes que são construídos pelas experiências da classe trabalhadora e permita que os sujeitos tenham o conhecimento de outras culturas, entendam a organização estrutural em que vivem e a 
importância do trabalho para si e para o outro, caminhando, assim, como projeto educativo na construção de uma formação mais próxima a omnilateralidade. Dessa forma, construir um conhecimento que leve os jovens e adultos trabalhadores brasileiros compreender o contexto social em que estão inseridos. Logo a contribuição da escola pública para o estudante da Educação de Jovens e Adultos passa por potencializar suas capacidades de lutar e reivindicar os seus direitos como sujeito de direito, uma concepção voltada para a formação de sujeitos que buscam apreender além do saber pedagógico.

Consideramos, nessa dimensão, que a Nova Política de Educação de Jovens e Adultos (NEJA) se configura numa dimensão formativa de unilateralidade dos sujeitos e foi elaborada como uma política de escolarização como expressão de uma dualidade educacional de novo tipo. Nessa perspectiva, Rummert, Algebaile e Ventura (2013) indicam: "Na atual forma histórica de dualidade educacional, o elemento novo é constituído pelas ofertas educativas que propiciam possibilidades de acesso a diferentes níveis de certificação, falsamente apresentados como portadores de qualidade social igual a das certificações às quais têm acesso a burguesia" (p. 273).

O programa NEJA pode ser enquadrado, assim, como modelo de política pública que visa, através de novas propostas curriculares elevar a escolarização e a certificação de jovens e adultos trabalhadores, buscando, sem grandes investimentos, impactar positivamente os dados estatísticos em relação ao nível de escolaridade da população mais pobre, bem como, apresentar para a população uma iniciativa original por parte do governo em relação ao cumprimento do direito à educação.

O referido programa foi criado pela Secretaria Estadual de Educação do Rio de Janeiro (SEEDUC) em parceria com a Fundação Centro de Ciências e Educação Superior à Distância do Estado do Rio de Janeiro ${ }^{4}$ (CONSÓRCIO CEDERJ). Essa parceria entre a SEEDUC e o Consórcio

\footnotetext{
${ }^{4}$ É um órgão vinculado à Secretaria de Estado de Ciência e Tecnologia - (SECT), desenvolve projetos nas áreas de graduação a distância (Consórcio CEDERJ); divulgação científica; prévestibular social; cursos de extensão (Formação Continuada de Professores) e os Centros de Educação de Jovens e Adultos (CEJA - Ensino de Jovens e Adultos).
} 
CEDERJ apresenta um trabalho destinado às escolas da rede estadual de ensino do Estado do Rio de Janeiro que ofertam a Educação de Jovens e Adultos na etapa do Ensino Médio, implantado a partir do primeiro semestre de 2013 com adesão compulsória nas escolas da rede estadual.

A NEJA entrou em vigor a partir da Resolução no $4951^{5}$ que intitula a "implantação das diretrizes curriculares para a educação básica nas unidades escolares da rede pública e dá outras províncias". Esse documento apresenta a proposta curricular do programa e ressalta detalhadamente a carga horária das disciplinas que serão ofertadas aos jovens e adultos.

Essa nova proposta se organiza em módulos e com materiais didáticos próprios para alunos e professores, auto reconhecida como uma mudança estrutural em relação ao currículo do Ensino Médio regular. O currículo do programa se organiza em quatro módulos com a duração total de dois anos letivos. A carga horária diária das aulas é de 03 horas e 20 minutos e se encontra organizada em 04 tempos de segunda a sexta-feira e, de acordo com o manual, podem ser ministradas nos turnos diurno, vespertino e noturno. A duração do tempo de cada disciplina do módulo é de 50 minutos diários. Os quatro tempos diários das aulas do programa NEJA são referentes às disciplinas obrigatórias. As disciplinas optativas ensino religioso e língua estrangeira - são ministradas uma vez por semana e ambas não são obrigatórias para a conclusão do curso. A disciplina ensino religioso será oferecida aos alunos em todos os módulos, porém acontecem antes de iniciar o turno ou no final, já a língua estrangeira somente no módulo IV.

Os quatro módulos ordenam as disciplinas escolares em língua portuguesa/literatura, matemática, ciências humanas que contemplam geografia, história, filosofia, sociologia e ciências da natureza que englobam biologia, física e química. Cada módulo tem a duração de seis meses e terá no mínimo cinco e no máximo sete disciplinas. Em todos os módulos da NEJA o aluno terá língua portuguesa/literatura e matemática.

\footnotetext{
${ }^{5}$ Resolução SEEDUC no 4951 de 04 de outubro de 2013 com base no processo no 03/001/5612/13.
}

História \& Ensino, Londrina, v. 25, n. 1, p. 139-157, jan./jun. 2019 
Os módulos se organizam por disciplinas, ou seja, as disciplinas voltadas para as ciências humanas estão destinadas a serem ofertadas nos módulos I e III, mais língua portuguesa/literatura, matemática e educação física. Nos módulos II e IV são ofertadas as disciplinas que fazem parte das ciências da natureza mais língua portuguesa/literatura, matemática, língua estrangeira e artes. As aulas são ministradas por um professor especialista em cada disciplina.

Esse modelo guarda em sua essência a tendência de controle do trabalho do professor e de uma oferta dos tempos de aula estruturada em módulos intercalados e com os conteúdos já pré-determinados e entregues ao professor durante a implementação do programa, através do material didático a ser usado em sala de aula. No manual da NEJA (2014, p. 16), aparece a seguinte indicação sobre o papel dos docentes: "repensar sua ação docente; estabelecer outro olhar sobre os limites e possibilidades dos alunos; exercitar um novo lócus enquanto mediador da construção do conhecimento e saberes.". Essa premissa indica o professor a uma tendência de executor/mediador, ou seja, o seu papel seria o de construir pontes ou de facilitador da aprendizagem do educando/a, gerando um esvaziamento do seu lugar como intelectual e autor de sua aula (MONTEIRO, 2007), tanto em suas dimensões de seleção de conteúdos, como nas suas opções metodológicas e, ainda, de escolha dos materiais didáticos para a sua aula.

Consideramos, assim que tal proposta pode ser analisada, numa perspectiva curricular crítica, na seguinte dimensão:

(...) o currículo é definitivamente, um espaço de poder. O conhecimento corporificado no currículo carrega as marcas indeléveis das relações sociais de poder. O currículo é capitalista. O currículo reproduz - culturalmente - as estruturas sociais. O currículo tem um papel decisivo na reprodução da estrutura de classes da sociedade capitalista. O currículo é um aparelho ideológico do Estado capitalista. O currículo transmite a ideologia dominante. O currículo é, em suma um território político. (SILVA,1999, p. 148).

Outro elemento de controle e esvaziamento do trabalho docente reside na redução de carga horária de determinas disciplinas em detrimento 
de outras. E mesmo indicando, no Manual, que a sua organização curricular deve "promover habilidades para o mundo do trabalho e para a vida social", se reduz, particularmente, os campos disciplinares como Ciências Humanas e Ciências da Natureza, que potencialmente poderiam contribuir para uma leitura do mundo e das estruturas sociais e naturais em que estão inseridos. Em relação a organização curricular do Ensino Médio regular, a NEJA tem uma redução em torno de mais de $60 \%$ nos tempos dessas disciplinas, pois o educando/a só cursa as disciplinas de Ciências Humanas nos módulos I e III e as disciplinas de Ciências Naturais nos módulos II e IV. O que implica, ainda, em função da intercalação dessas disciplinas, num processo de descontinuidade pedagógica, para docentes e discentes, pois o educando/a cursa tais disciplinas em um semestre e só vai ter contato novamente com aquela área do conhecimento seis meses depois.

Por fim, vale destacar que esse tipo de oferta de política de educação assentada em uma dualidade educacional de novo tipo produz sobre os/as educandos/as, ainda, efeitos de uma socialização/moralização conservadora (NEVES, 2005), onde se estabelece uma transferência de responsabilidade para o sujeito sobre o equacionamento das desigualdades sociais:

\begin{abstract}
A proposta metodológica procura valorizar a experiência de cada aluno, que é visto como sujeito construtor de conhecimento, e a própria experiência de vida adquirida na educação extraescolar é o ponto de partida e referencial permanente para outras aprendizagens. Essa nova metodologia representa uma promessa de confirmar um caminho de desenvolvimento de todas as pessoas, de todas as idades. Dessa forma, essa nova proposta poderá atingir seu objetivo maior: construir uma sociedade mais justa, mais desenvolvida, mais igualitária e humana (RISOLIA, 2014, p. 4).
\end{abstract}

Essa citação aponta para um entendimento de estrutura social, na qual a sua construção depende, em forte medida, do processo de formação humana, ou seja, apreende a escolarização do sujeito como elemento fundamental para que ocorra a ascensão social individual e, que consequentemente a equalização social de forma ampla.

A intencionalidade que se encontra nesse parágrafo do manual de orientações do programa destacado acima é a de transferir uma 
responsabilidade aos sujeitos. Apontar que será através do processo de escolarização que teremos uma sociedade que apresente uma estrutura social mais 'justa, desenvolvida, igualitária e humana' é um discurso pedagógico que se insere na dualidade educacional de novo tipo, anteriormente citada, marcadamente reforçadora da dualidade estrutural em educação, pois os níveis de oferta e qualidade de escolarização para a classe trabalhadora é diametralmente oposta àquela garantida para outras classes sociais ou frações de classe.

Culpabilizar os sujeitos pela sua realidade é uma estratégia da estrutura capitalista para manter a ordem vigente e gerar nos jovens e adultos trabalhadores uma busca constante por uma formação que vise, exclusivamente possiblidade de empregabilidade precária, esvaziando, dessa forma, o potencial emancipador da escolarização de jovens e adultos. $\mathrm{Na}$ lógica expressa nas diretrizes da NEJA a escolarização deveria contribuir para a formação de uma nova capacidade técnica na perspectiva de humanizar as relações sociais, em uma formação básica da classe trabalhadora para aceitar a cidadania tutelada e a preparação geral para o trabalho adequado ao contexto de reestruturação produtiva, marcado pelo desemprego estrutural e, principalmente pela precarização das relações profissionais (NEVES, 2005).

A formação desse homem colaborador, no cenário histórico apontado, carrega explicitamente a tentativa de neutralização ou apagamento da perspectiva dos conflitos e antagonismos de classe. Portanto, o processo de coesão social é simples e depende de uma sociedade civil ativa, na qual os indivíduos, através do diálogo, da tolerância, e da escolarização, constroem o bem comum e superam suas realidades de pobreza. Os conflitos, as contradições e as possibilidades de luta coletivas, são completamente extintas e a responsabilidade pela pobreza e/ou exclusão social é individual, como também, obviamente, é individual a luta pela sua possível superação, que tem na escolarização - mesmo precarizada - uma de suas apostas e caminho. 


\section{O material didático da disciplina de História do NEJA: tensões entre possiblidades emancipatórias e prescritivas de trabalho docente.}

Os materiais didáticos da NEJA, na disciplina de História, foram selecionados como objeto de estudo na intenção de identificar em seu teor, possibilidades de construção do conhecimento histórico escolar na educação de jovens e adultos emancipatório para docentes e discentes.

O material didático não deve ser entendido somente como sendo uma seleção de conteúdos e atividades, pois ao mesmo tempo que ele permite controlar o processo de escolarização do público alvo, ele abre brechas mais autônomas em seu uso. Reconhecemos que o livro didático apresenta na sua estrutura uma intencionalidade na seleção dos conteúdos, nas indagações que são propostas para o professor e educando/a e nos textos que o compõem, porém o seu uso, dependem de um processo que foge do controle da burocracia educacional; as dinâmicas de aula que são geradas na mobilização de conteúdos/textos/temas de um livro didático são únicas e fortemente marcada pela ação ativa de professores e estudantes e ainda, pelo contexto onde está inserida a comunidade escolar.

A disciplina de História na estrutura curricular do programa NEJA é ofertada nos módulos I e III, com dois tempos semanais em cada módulo e em função dessa redução de carga horária, supomos, ocorreu uma seleção de conteúdos para o programa em comparação aos conteúdos normalmente presentes no Ensino Médio regular da rede. Destacamos, porém, que essa redução/escolha não dialoga com a realidade dos/das educandos/as e de suas especificidades político-pedagógicas enquanto sujeitos jovens e adultos trabalhadores, fluminenses e brasileiros, em processo de escolarização. A seleção de conteúdos faz um corte temporal, a saber: séculos XIX, XX e XXI, porém estrutura os conteúdos em diálogo frontal com a organização de conteúdo assentado em linearidade e causa/efeitos dos fenômenos históricos, a partir do século XIX. E ocorre a clara adesão a organização clássica das eras históricas e do ensino tradicional de História (BITTENCOURT, 2004). 
Outra característica marcante é a centralidade do sujeito histórico Estado, como propulsor central dos acontecimentos históricos, trazendo pouca centralidade para os outros sujeitos históricos. Essa tendência fica bem explicita nos títulos / temas das unidades dos módulos, onde clássicos temas históricos da história política estão presentes, como: Conquista da América; Brasil Colônia; Primeiro e Segundo Reinado; Imperialismos/Colonialismo; Nacionalismos/Guerras do século XX, etc. Essa dinâmica de organização temporal e de temas no material, significativos para a historiografia tradicional, Ihe confere um caráter de pouca inovação e de reprodução, aligeirada e reduzida, de um modelo, ainda, tradicional de organizar o material didático na disciplina de História.

Mas, em uma apreciação mais pormenorizada do referido material didático, identificamos brechas indutoras de uma prática docente mais emancipatória e para colocar luz sobre tal análise, vamos identificar e problematizar como o tema Trabalho aparece e é mobilizado ao longo dos quatro volumes que compõe o material didático do programa. Na unidade 01, no volume II do módulo I, cujo título é o Século XIX: as ideias políticosociais e os movimentos rurais e urbanos o tema Trabalho é apresentado na seguinte definição:

(...) trabalho é, ao mesmo tempo, fonte de realização - já que é através dele que "ganhamos o pão de cada dia" -, e espaço de privação, sofrimento e dor - já que nem sempre trabalhamos como queremos, no tempo que escolhemos e nas condições que gostaríamos. A experiência de trabalhar nem sempre nos lembra $o$ ato criativo que transforma o mundo e nos transforma, que cria coisas novas. Na maioria das vezes, vivenciamos o trabalho como algo que gera riqueza para uma pessoa ou empresa, e que faz pouco sentido para nós mesmos. E se pensarmos nas condições às quais os trabalhadores foram submetidos ao longo do tempo, observamos que o trabalho, normalmente, está associado a dor - imagine que a palavra trabalho deriva de um instrumento muito antigo, o tripalium, espécie de tridente usado para castigar e torturar pessoas. (NEJA, Ciências Humanas e suas Tecnologias, História, Manual do Aluno, módulo I, volume II, p. 144).

Tal citação revela que o trabalho é visto como a venda da mão de obra para o modelo de produção capitalista e que tem a sua marca histórica 
a partir da revolução industrial. Com a chegada das máquinas e das indústrias o trabalho passou a ser calculado e transformado em valor monetário. Essa abordagem sobre a categoria trabalho aponta para a discussão na qual o trabalho é a execução mecânica da ação humana que resulta em uma mercadoria e a mesma será vendida comercialmente pelo dono da fábrica sem que ocorra a criação e a transformação da matéria prima em mercadoria, ou seja, produzida por meio de um processo criativo elaborada pelo homem.

Abordado de forma factual esse trecho pode se configurar com uma mera definição do que é o trabalho e sua historicidade, apartado de sua materialidade, contradições e principalmente como experiência cotidiana dos/das educandos/as da EJA. Mas a simples problematização do trecho "Na maioria das vezes, vivenciamos o trabalho como algo que gera riqueza para uma pessoa ou empresa, e que faz pouco sentido para nós mesmos" é um indutor de uma reflexão coletiva sobre as contradições do mundo do trabalho; ao se construir coletivamente o "sentido" para essa premissa, através de debates, de filmes, de relatos das experiências laborais e de exploração de professores e educando/as, de produção textual individual e coletiva, estamos marcando e construindo, no cotidiano escolar uma concepção de Trabalho que os aproxima de uma perspectiva formativa de omnilateralidade.

Outra brecha trazida pelo material para uma abordagem mais crítica pode ser identificada nesse trecho da unidade em análise, onde o Trabalho é apresentado em suas dinâmicas especificas nos marcos do capitalismo industrial após a Revolução Industrial e já indicando os seus impactos sobre os trabalhadores:

É certo que o trabalho assumiu novas formas a partir daí. A parcialização da produção e a especialização de trabalhadores em tarefas cada vez mais pontuais tornaram a repetição mecânica cada vez mais intensa na jornada de trabalho. O crescente controle sobre os tempos e os movimentos do trabalhador durante o trabalho levou ao surgimento da chamada administração científica do trabalho ou taylorismo, já que se baseia nos estudos de Frederick Taylor (1856-1915). Além disso, mais tarde, tivemos a divisão do trabalho entre vários operários, com a introdução 
das linhas de montagem características do chamado fordismo. Estes dois mecanismos de trabalho e produção permitiriam um aumento da produção, a redução dos custos e o aumento dos lucros dos empresários. (NEJA, Ciências Humanas e suas Tecnologias, História, Manual do Aluno, módulo I, volume II, p. 147).

Esse trecho aponta para os modelos de produção industrial que revelam uma concepção de trabalho que aliena o trabalhador em relação a sua força de trabalho, o papel que ele ocupa nessa produção, o reconhecimento do seu trabalho que lhe é negado e, também, a presença marcante da exploração entre os seres humanos e principalmente na ampliação da mais-valia.

O fragmento é a materialidade das contradições existentes na produção de um material didático por redes oficiais; mesmo cercado de controle, os autores conseguem, também, abrir brechas em suas escritas, em diálogo com perspectivas educacionais mais emancipatórias. Retornando a contribuição do Poulantzas (1975), o pessoal do Estado, - nesse caso, os autores do material - podem anunciar posicionamentos contrários aos ditames gerais das políticas de Estado, pois consideramos que no interior da aparelhagem do Estado, tais sujeitos estão inseridos na luta de classe e está se materializa e se expressa nas brechas produzidas pelos autores em um material tão prescritivo; e a potência dessas brechas produzidas no interior da aparelhagem estatal pode exponencialmente gerar novas e boas práticas docentes, mais autônomas e emancipatórias para estudantes e professores no uso do material na escola.

As charges, a seguir, são mais um espaço de materialidade dessas brechas produzidas pela opção e posicionamento de seus autores. A primeira charge (figura 01) ilustra e problematiza o papel que o trabalhador ocupa durante o trabalho fabril e a segunda charge (figura 02) aborda a temática da mais valia e dos movimentos sociais. 
Figura 1 - Charge da seção Relações de trabalho nos séculos XVIII e XIX

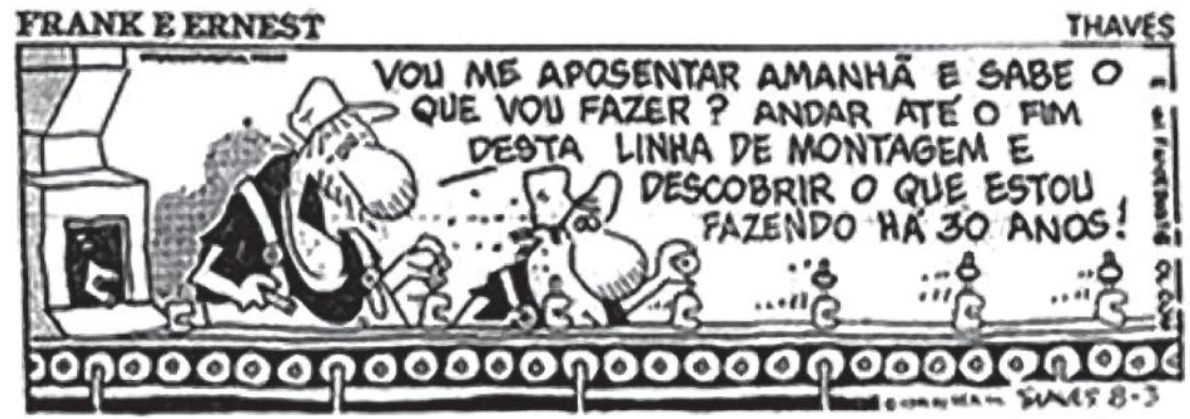

berel do 8nesil, 19 de teretio dal 1997.

Fonte: NEJA - Nova Política de Educação de Jovens e Adultos. Ciências humanas e suas tecnologias: História. Manual do Aluno. Módulo I. Volume II. Rio de Janeiro: Fundação CECIERJ, 2012.

Figura 2 - Charge da seção chamada Movimentos sociais dos trabalhadores no século XIX

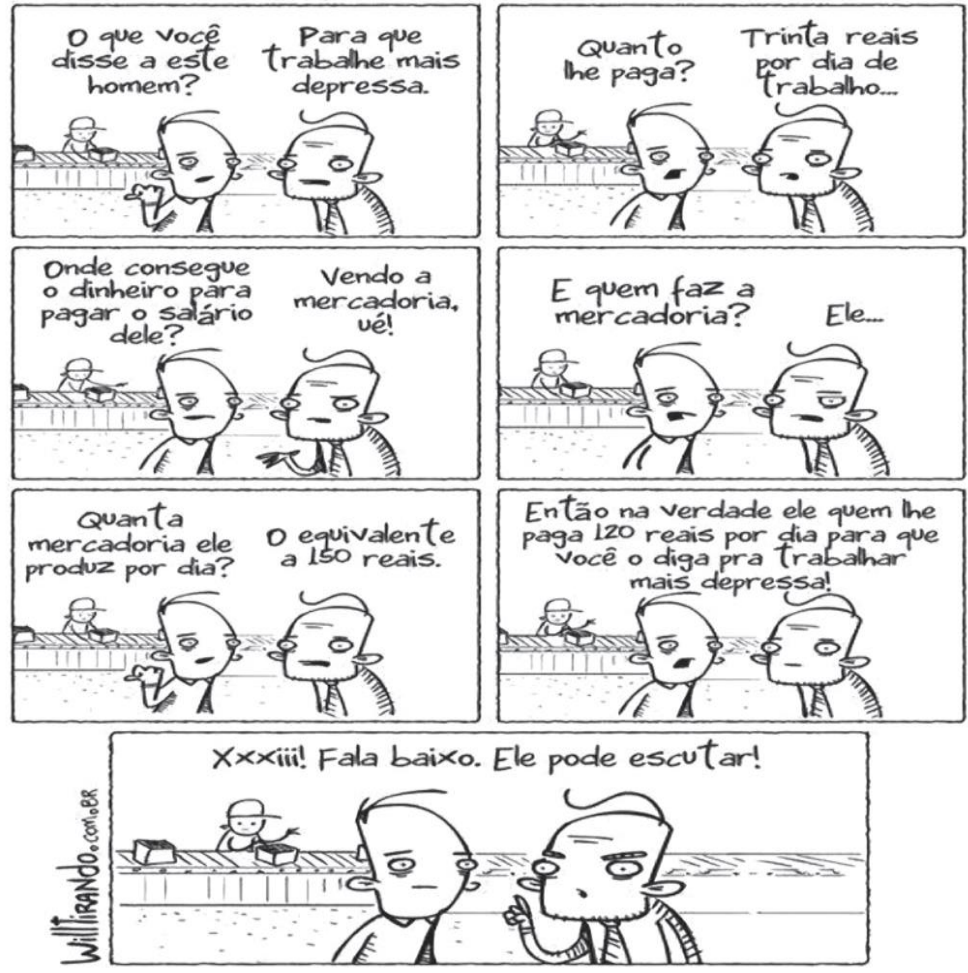

Fonte: NEJA - Nova Política de Educação de Jovens e Adultos. Ciências humanas e suas tecnologias: História. Manual do Aluno. Módulo I. Volume II. Rio de Janeiro: Fundação CECIERJ, 2012. 
Essas ilustrações evidenciam a discussão sobre a concepção de trabalho alienado e trabalho produtivo. O material didático do aluno destaca com base nessas ilustrações as condições de vida que os trabalhadores enfrentaram no período da revolução industrial e nos períodos posteriores e ainda, a função fragmentada do seu trabalho em relação à produção de mercadoria.

A segunda ilustração reconhece a precarização do trabalho após a revolução industrial e que gerou profundas mudanças na vida dos trabalhadores. Essa charge permite ao docente em diálogo com as experiências dos estudantes construir algumas questões problematizadoras numa perspectiva da omnilateralidade, como: O trabalho é somente aquela ação que em troca recebemos um salário? Quais são as condições de trabalho dos alunos? Por que o trabalho está atrelado ao nível de escolaridade dos sujeitos? Essas indagações não estão presentes na proposta curricular do programa, mas o material didático ofertado aos alunos, apresenta ao professor fragmentos e ilustrações no qual destacam a categoria Trabalho em sua perspectiva do princípio educativo, por exemplo.

Assim, reconhecemos que material didático em análise, apresenta em alguns momentos uma concepção de Trabalho que visa à formação humana para a emancipação, porém isso não é claramente definido nas atividades proposta no material didático, por exemplo, bem como na sua concepção político-curricular. Logo, cabe ao professor revelar durante o seu trabalho, através da autonomia e da seleção do material, quais conteúdos e recursos apresentados podem, por exemplo, mobilizar uma determinada concepção de Trabalho a ser construída e problematizada com seus educandos/as.

De acordo com Maria Teresa Esteban a sala de aula pode ser considerada:

(...) lugar múltiplo onde se cruzam saberes e desejos diversos e que convida ao diálogo, mesmo quando só dá espaço para o diálogo interior. Sala de aula, lugar que procura organizar-se no singular, ocultando que sua singularidade está na pluralidade que a compõe, impedindo que os trajetos, desejos e possibilidades peculiares se expressem e se afirmem fazendo que muitos tentem se adequar ao ritmo imposto, à tarefa dada, aos tempos fixos, 
ao movimento previsível e uniforme, que obrigam a deixar de fora a turbulência da vida e desobrigam a vivê-la, ainda que por pouco tempo, em toda sua intensidade. (ESTEBAN, 2001, p. 3).

A autonomia do professor durante a realização da proposta curricular do programa NEJA permitirá que os alunos construam novas interpretações diante do que se encontra estabelecido no material. O diálogo, a experiência de vida, os interesses e desejos que os jovens e adultos trabalhadores apresentam na sala de aula vai tecer a construção do saber pedagógico. Diante disso, é importante que o docente tenha a clareza durante a sua ação pedagógica qual formação humana está se comprometendo a proporcionar aos sujeitos-educandos/as com o seu trabalho. O professor durante a execução do seu fazer pedagógico realiza ações que visam à formação humana para a emancipação ou uma formação humana para unilateralidade? Essa é uma das diversas indagações que o docente deve realizar ao longo da sua jornada profissional uma vez que a sua prática deve estar em constante reflexão e em resistência aos controles burocráticos sobre a sua autonomia e o seu papel de autor de seu fazer e saberes pedagógico.

E para efeito de considerações finais indicamos que a educação sozinha não permitirá a libertação/emancipação humana. Ela está inserida em uma sociedade que apresenta uma organização que necessita ser combatida em um contexto mais amplo e diversificado; assim os limites e potencialidades da educação não deve ser encarada em uma perspectiva micro, considerando a oferta educacional em uma dimensão salvacionista e mas sim macro, pois a educação agrega em sua natureza um importante papel para o controle da hegemonia e ao mesmo tempo de construção da contra hegemonia e no devir histórico apontado por Paulo Freire aos professores e professoras, podemos considerar que a educação sozinha não transforma a sociedade, sem ela tampouco a sociedade muda. 


\section{Referências}

BITTENCOURT, Circe. Ensino de história: fundamentos e métodos. São Paulo: Cortez, 2004.

ESTEBAN, Maria Teresa. Avaliar: ato tecido pelas imprecisões do cotidiano. In: GARCIA, R.L., org., Novos olhares sobre a alfabetização, São Paulo, Cortez, 2001.

FRIGOTTO, Gaudêncio. A formação e a profissionalização do educador: novos desafios. In: SILVA, Tomaz Tadeu e GENTILI, Pablo (orgs.). Escola S.A. quem ganha e quem perde no mercado educacional no neoliberalismo. Brasília (DF): CNTE, 1996.

MANACORDA, Mario Aligheiro. Marx e a Pedagogia Moderna. São Paulo: Cortez, Autores Associados, 1991.

MONTEIRO, Ana Maria. Professores de história: entre saberes e práticas. Rio de Janeiro: Mauad, 2007.

NEJA - Nova Política de Educação de Jovens e Adultos. Ciências humanas e suas tecnologias: História. Manual do Aluno. Módulo I. Unidade 1. Rio de Janeiro: Fundação CECIERJ, 2012. 2v.

NEJA - Nova Política de Educação de Jovens e Adultos. Ciências humanas e suas tecnologias: História. Manual do Aluno. Módulo III. Unidade 1. Rio de Janeiro. Fundação CECIERJ, 2012. 2v.

NEVES (org.) A nova pedagogia de hegemonia: estratégias do capital para educar o consenso. São Paulo: Xamã, 2005.

POULANTZAS, Nicos. As classes sociais no capitalismo de hoje. Tradução de Antônio Roberto Neiva Blundi. Zahar Editores: Rio de Janeiro, 1975.

Resolução no 4951. Fixa diretrizes para a implementação das matrizes curriculares para a educação básica nas unidades escolares da rede pública e dá outras providências. Rio de Janeiro, 04 de outubro de 2013.

RISOLIA, Wilson. Manual do programa. Rio de Janeiro: Fundação CECIERJ, 2014.

RUMMERT, Sonia Maria. A educação e as teses de inclusão social. Revista Espaço Acadêmico, n. 58, ano V, Maringá, p. 58-64, mar. 2006.

RUMMERT, Sonia Maria. Educar e qualificar: caminhos e descaminhos da educação de jovens e adultos trabalhadores. Revista Perspectiva, Florianópolis, v. 31, n. 2, 405-423 maio/ago. 2013. 
RUMMERT, Sonia Maria; ALGEBAILE, Eveline; VENTURA, Jaqueline. Educação da classe trabalhadora brasileira: expressão do desenvolvimento desigual e combinado. In: Revista Brasileira de Educação v. 18 n. 54 jul.set. 2013.

SAVIANI, Demerval. Trabalho e educação: fundamentos ontológicos e históricos. In: Revista Brasileira de Educação, v.12, n.34, pp.152-165. jan. /abr. 2007.

SEGNINI, L. Educação e Trabalho: uma relação tão necessária quanto insuficiente. São Paulo Perspectiva. vol.14 no.2 São Paulo Apr. /Jun 2000

SILVA, Tomaz Tadeu da. Documentos de identidade: uma introdução às teorias do currículo. Belo Horizonte: Autêntica, 1999.

TARDIF \& LESSARD. O Trabalho Docente. Rio de Janeiro: Vozes, 2009. 